\title{
Erratum: Disability and poverty - Reflections on research experiences in Africa and beyond
}

\author{
Authors: \\ Arne H. Eide ${ }^{1}$ \\ Benedicte Ingstad $^{2}$ \\ Affiliations: \\ ${ }^{1}$ SINTEF Technology and \\ Society, Oslo, Norway \\ ${ }^{2}$ Department of Community \\ Medicine, University of Oslo, \\ Norway \\ Correspondence to: \\ Arne Eide \\ Email: \\ arne.h.eide@sintef.no \\ Postal address: \\ SINTEF Technology and \\ Society, PB 124 Blindern, \\ $\mathrm{N}-0314$ Oslo, Norway \\ Date: \\ Published: 12 Dec. 2013 \\ How to cite this article: \\ Eide, A.H. \& Ingstad, B., \\ 2013, 'Disability and poverty \\ - Reflections on research \\ experiences in Africa and \\ beyond', African Journal \\ of Disability 2(1), Art. \#31, \\ 1 page. http://dx.doi. \\ org/10.4102/ajod.v2i1.31-1 \\ Note: \\ Doi of original article: http:// \\ dx.doi.org/10.4102/ajod. \\ v2i1.31

\section{Copyright:} \\ (C) 2013. The Authors. \\ Licensee: AOSIS \\ OpenJournals. This work \\ is licensed under the \\ Creative Commons \\ Attribution License.

The below reference was missing from the published form of this article:

Hansen, C. \& Sait, W., 2011, '”We too are disabled": Disability grants and poverty politics in rural South Africa', in A.H. Eide \& B. Ingstad (eds.), Disability and poverty a global challenge, pp. 93 -118, The Policy Press University of Bristol, Bristol.

The publisher regrets this error. 